\title{
FORMAS DE MOBILIZAÇÃO SUBJETIVAS DOS ENFERMEIROS INTENSIVISTAS ITALIANOS NO CONTEXTO DE ENFRENTAMENTO DA COVID-19.
}

\author{
SUBJECTIVE FORMS OF MOBILIZATION OF ITALIAN INTENSIVE \\ CARE NURSES IN THE CONTEXT OF COPING WITH COVID-19. \\ Julius Christie de Araújo Brandão - juliusashley@hotmail.com ${ }^{1}$ \\ Denilson Bezerra Marques - denilson.marques@ufpe.br ${ }^{2}$ \\ Rosane Maria Alencar da Silva - rmas3@cin.ufpe.br ${ }^{3}$
}

1

Graduado em Educação Física (Centro Universitário de João Pessoa) e em Enfermagem (Faculdade Santa Emília de Rodat). Mestre em Gestão Pública (UFPE). Técnico Adm. em Educação Enfermeiro (UFPB) Orcid/Lattes: https://orcid. org/oooo-0001-6518-5067 2

Psicanalista e Doutor em Sociologia (UFPE). Professor Associado do Departamento de Ciências Administrativas da UFPE e do Mestrado em Gestão Pública (MGP/UFPE) Membro do Fórum do Campo Lacaniano de Recife. Orcid/Lattes: https://orcid. org/oooo-0002-3066-8242 3

Pedagoga e Doutora em Sociologia (UFPE). Professora Associada do Departamento de Sociologia da UFPE e do Mestrado em Gestão Pública (MGP/ UFPE). Coordenadora do Programa Institucional de Bolsas de Iniciação à Docência em Ciências Sociais (PIBID) da UFPE. Orcid/Lattes: https://orcid. org/oooo-0002-8132-7915
RESUMO: A partir da mobilização subjetiva buscou-se entender como enfermeiros italianos que trabalham com a Covid-19, buscaram transformar dificuldades e anomalias da organização do trabalho em prazer. Fonte dos dados - Retirado de matéria jornalística disponibilizada livremente na internet, traz cinco relatos de enfermeiros intensivistas que compõe o corpus da pesquisa. Metodologia - Modelada de forma que a unidade do discurso fosse uma unidade intencional do tema. Essa intenção refere-se à interação do deslocamento (freudiano) com a proposta dejouriana, tendo como parâmetro as categorias da mobilização subjetiva. Resultados - Os elementos da mobilização subjetiva encontrados foram: enfrentamento inteligência prática e reconhecimento. Conclusão - Identificou-se um fenômeno de transversalidade inerente a estes elementos. Esta não é prevista em Dejours e nem em outros trabalhos similares.

palavras-chave: Covid-19, Mobilização subjetiva, Deslocamento. Organização do trabalho.

ABSTRACT: Based on subjective mobilization, we sought to understand how Italian nurses who work with Covid-19, sought to transform difficulties and anomalies in the organization of work into pleasure. Source of data - Taken from journalistic material freely available on the internet, it brings five reports of intensive care nurses that make up the corpus of the research. Methodology - Modeled in such a way that the discourse unity was an intentional unity of the theme. This intention refers to the interaction of displacement (Freudian) with the Dejourian proposal, taking as a parameter the categories of subjective mobilization. Results - The elements of subjective mobilization found were coping, practical intelligence and recognition. Conclusion - A transversal phenomenon inherent to these elements was identified. This is not foreseen in Dejours or in other similar works.

KEYwords: Covid-19, Subjective Mobilization, Displacement, Work Organization.

Data de Submissão: 16/12/2020

Data de Revisão: 16/02/2021

Data de Aceitação: 17/02/2021 


\section{PANORAMA GERAL DA COVID-19}

A COVID-19 teve origem em Wuhan ${ }^{1}$, província de Hubei, China, no final de dezembro de 2019. COVID-19 é o nome atribuído pela Organização Mundial da Saúde (OMS) à doença provocada pelo novo coronavírus SARS-COV-2². Em 11 de março de 2020 a OMS declarou a COVID-19 como uma pandemia ${ }^{3}$. Pandemia não é uma palavra a ser usada de forma leviana ou descuidada, observa Tedros Adhanom, diretor-geral da OMS. É uma palavra que, se mal utilizada, pode causar medo irracional ou aceitação injustificada de que a luta acabou, levando a sofrimento e morte desnecessários. Em 21 de julho de 2020 o número global de casos confirmados de COVID-194 já soma mais de 17 milhões, com aproximadamente 674 mil mortos e quase 11 milhões de pessoas recuperadas. Estes números são bastantes dinâmicos, e, por enquanto, crescentes, o que implica destacar que: na data de leitura deste artigo é possível que os números da doença estejam em patamares muitos acima do momento em que se deciciu, neste trabalho, fotografar a realidade social no mundo. A diferença dos números não inviabiliza a discussão teórica que será abordada, apenas se refere ao carater efêmero dos indicadores da doença. $\mathrm{O}$ vírus se espalhou rapidamente, mesmo em países desenvolvidos como: China, EUA, Espanha, Itália, Coréia do Sul, França, Alemanha, Inglaterra, Suécia e também em paises menos afortunados. É uma pandemia de proporções planetárias, pois afeta o funcionamento social e econômico de todos os paises em mesmo momento histórico. O isolamento social foi estratégia adota por quase todo o planeta para enfrentar a letalidade da pandemia.

\section{COVID-19 E SUBJETIVAÇÃO}

O apelo ao trabalho tem potencial para modificar as relações de afeto interpessoais, quer sejam no ambiente familiar ou fora deste. É relativamente fácil escutarmos a expressão: "passamos mais tempo na empresa, com nossos colegas de trabalho do que com nossa família e amigos pessoais". Na modernidade o capitalismo nos leva, de forma colonizadora, ao mundo corporativo, onde cada vez mais estruturamos nossas relações sociais imediatas em detrimento de outros espaços pessoais.

Os aspectos psicológicos relativos à pandemia da Covid-19 têm sido objetos de estudos de diferentes áreas do saber. A organização do trabalho que dela decorre sinaliza, de forma geral, um conflito que se situa entre a promessa de realização profissional e a frustração decorrente da percepção de não respeitos por parte da população

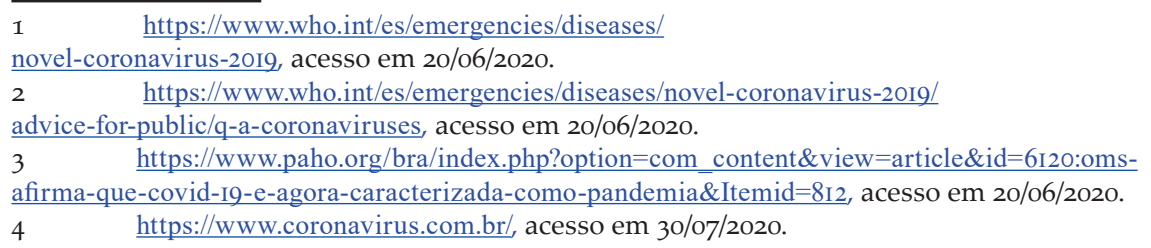


que negligencia as recomendações das autoridades sanitárias. Nesse conflito encontra-se o que Dejours (1994) nomeiaria como uma troca intersubjetiva de desejos que anseiam a obtenção de prazeres superficiais e descartáveis e até ameaçadores à própria integridade psíquica do trabalhador.

À partir de Dejours (1994) observa-se que a organização do trabalho cria necessidades artificiais que produzem um tipo de esvaziamento de si mesmo que os sujeitos vivenciam como um imperativo, uma lei, ou mesmo uma subversão do senso crítico.

Neste momento de pandemia, que permeia o capitalismo moderno, ser um trabalhador se aproxima do sujeito desejante de si próprio, tal como preconizado por Dejours (2004). Esse sujeito estaria sublimado na obtenção de sua imagem profissional, através do planejamento de sua carreira, prestígio social e estilo de vida. E este desejo, como consequência da indistinção do coronavirus, não existe apenas entre os que detêm o poder, científico, político, financeiro e econômico, ele é observado em todos os sujeitos independentes de sua condição, intelectual, ideológica, profissional, social e econômica.

Em torno do tema pandemia, temo discursos que assujeitam os sujeitos. A forma com que o apelo da mídia coloniza os sujeitos desperta, nestes, necessidades inconscientes de se ajustar às figuras idealizadas de trabalhador que transcende estas barreiras sociais, transformando estes sujeitos em escravos de si próprio. Realidade e prazer se tencionam entre si, trazendo aos sujeitos a sensação de vazio (Bauman, 1999, 2001 e 2008) que nunca são preenchidos.

Estimulados pelos discursos midiáticos que transformam necessidades artificiais em necessidades básicas, há que se problematizar e questionar a aderência desta transformação nos processos de subjetivação dos sujeitos em suas interações com a organização do trabalho neste momento da pandemia.

Todo trabalho precisa de uma organização, de uma lógica de funcionamento para que a produção aconteça como desejado. Nas organizações, públicas ou privadas, a organização do trabalho é, geralmente, determinada pelo mais alto nível hierárquico da gestão. Segundo Gaulejac (2007), na sociedade hipermoderna cada indivíduo pode ser ao mesmo tempo produtor e produto do sistema, ser $\mathrm{o}$ ator e $\mathrm{o}$ agente dele, fazê-lo funcionar, tanto quanto suportá-lo. Neste sentido, o que a organização do trabalho preconiza é a racionalidade e otimização da produção e a maximização do lucro, para as organizações privadas. Já para as organizações públicas, esta racionalidade se reflete em aumento da eficiência e eficácia organizacional demandadas pela sociedade através da prestação do serviço público. No que concerne ao enfrentamento da pandemia idealiza-se um nível de comprometimento, público e privado, calcados na atenção das necessidades de todos os indivíduos do planeta.

Os mecanismos de adaptação ao sofrimento no trabalho também operam nos processos de subjetivação vias técnicas de si, os quais via- 
bilizam o exercício eficaz na atividade (Bouyer et.al, 2006). Levando em consideração esses mecanismos de adaptação dos trabalhadores, o que os levam a se sentirem satisfeitos ou insatisfeitos no seu ambiente de trabalho? Como a pandemia da Covid-19 convoca suas emoções e racionalidades?

Bouyer et al (2006) analisando as condições da organização do trabalho nas equipes de socorristas do SAMU, observa que muitas vezes não é possível compreender "critérios de eficácia", "métodos" empregados, "qualidade" e "eficiência operacional" sem adentrar a dimensão psicológica dos seres humanos que prestam um serviço produtivo, pois as técnicas e os métodos que fazem um salvamento serem eficientes, que se mostram eficazes na luta contra morte de um paciente, pertencem ao terreno obscuro das subjetividades dos profissionais de emergência (Bouyer et al, 2006).

Anjos (2013) afirma que a organização do trabalho é o ato ou ação de se estabelecer as bases para o esforço, pelo investimento das ações. Historicamente, o termo ganha notoriedade quando passa a designar o modelo taylorista de organização do trabalho baseado nos princípios da administração científica do trabalho (Anjos, 2013). O objetivo desse sistema é o aumento da produtividade que seria conquistada se houvesse uma reprimenda da "vadiagem", caracterizada como as fases durante as quais os operários pensam sobre o trabalho, trabalhando num ritmo menor do que aquele que poderiam ou deveriam adotar (Dejours, 2015).

No mundo globalizado e competitivo, cada vez mais se demonstra a importância do trabalho na vida das pessoas, se refletindo no processo de desenvolvimento da família, do Estado e da sociedade. Vários pesquisadores (DEJOURS, 2004, 2011a, 2011b, 2015; FACAS, 2013; MENDES, 2007; GAULEJAC, 2007; BOUYER et al, 2006; ANTUNES e PRAUN, 2015; PAGÈS et al, 1987), procuram entender de que forma o trabalho pode ser menos sofrido ou até mesmo, mais prazeroso. As relações de poder dentro das organizações ficam mais evidentes e trazem consequências sociais e psicológicas para o coletivo de trabalhadores (FARIA, 2007; PAGÈS et al, 1987; GAULEJAC, 2007).

Neste sentido, podemos questionar: até que ponto as recentes transformações na organização do trabalho, decorrentes da pandemia da Covid-19, trouxeram impactos diretos e indiretos na subjetividade do trabalhador? O que mudou quando comparado ao momento anterior da pandemia? Como a quarentena e o distanciamento social se inserem, teoricamente, nesse contexto? Como as manifestações de reconhecimento e de carinho, em todas as partes do planeta, são absorvidas por estes profissionais? "Aprendi a sorrir com o olhar", ou "desligo os respiradores e os ajudo a morrer em paz.". São relatos provocadores de reflexões de alguns dos diversos profissionais que atuam no combate à Covid-19. Quais recursos são esses que estão sendo mobilizados

$5 \quad$ https://www.agazeta.com.br/revista-ag/comportamento/tecnica-de-enfermagemfala-sobre-a-rotina-com-pacientes-infectados-em-uti-0420, acesso em 20/06/2020.

6 https://www.bbc.com/portuguese/geral-52329427, acesso em 20/06/2020. 
para se concentrarem neste "olhar" ou nesta "ajuda"? Essa capacidade de transformar o sofrimento no trabalho em prazer está relacionada com a mobilização subjetiva, que é o engajamento do sujeito na construção e evolução da organização do trabalho em termos de esforços de inteligência e esforços para construção de opiniões sobre a melhor maneira de superar as contradições e as dificuldades (DEJOURS, 2011a). É a partir do fenômeno da mobilização subjetiva que buscaremos entender como os enfermeiros intensivistas italianos, que atuam na linha de frente da pandemia da Covid-19, se colocam diante da ambiguidade de prazer e sofrimento.

\section{A MOBILIZAÇÃO SUBJETIVA E A ORGANIZAÇÃO DO TRABALHO}

Os estudos em Psicodinâmica do Trabalho (PdT) remontam aos anos 1980, na França, com Christopher Dejours. A PdT tem como objeto de estudos a relação entre a organização do trabalho e a saúde mental dos sujeitos. Decorre desse objeto pesquisas que buscam entender as situações que dão origem ao sofrimento dos trabalhadores, ao mesmo tempo em que estendem as reflexões às suas subjetividades.

Segundo Dejours, Abdoucheli e Jayet (1994, p.15)

o sofrimento, designa então, em uma primeira abordagem, o campo que separa a doença da saúde. Dentro de uma segunda acepção, o sofrimento designa um campo pouco restritivo. Ele é concebido como uma noção específica válida em Psicopatologia do trabalho, mas certamente não transferível a outras disciplinas, notadamente à psicanálise. Entre o homem e a organização prescrita para a realização do trabalho, existe, às vezes um espaço de liberdade que autoriza uma negociação, invenções e ações de modulação do modo operatório, isto é, uma invenção do operador sobre a própria organização do trabalho, para adaptá-la às suas necessidades, e mesmo para torná-la mais congruente com seu desejo. Logo que esta negociação é conduzida a seu último limite, e que a relação homem-organização do trabalho fica bloqueada, começa o domínio do sofrimento - e da luta contra o sofrimento.

Da psicanálise, Dejours (1994) traz o percurso de desenvolvimento da personalidade, cuja origem remonta a infância e que deixa marcas na subjetividade. Estas marcas são os sintomas que se manifestam no sofrimento vivido pelo sujeito. $\mathrm{O}$ percurso empreendido pelo sintoma é singular e convoca sua interpretação a partir do processo de desenvolvimento psicoafetivo da criança. No ambiente organizacional, esse sintoma ocupa lugar central na interpretação da relação psíquica desse adulto com a organização do trabalho. O sofrimento aqui tratado diz respeito a como o sujeito deseja e, por consequência, sofre por isso, uma vez que está sempre em falta e, portanto, aspira pelo que não possui (Facas, 2009), não sem obstáculos, não sem incidentes, até que se estabilize, em suas forças e suas fragilidades, o EU adulto. Os 
obstáculos com os quais se choca o desenvolvimento psicoafetivo da criança ocuparão posteriormente um lugar central na relação psíquica do adulto com o trabalho. A angústia, o sofrimento e as preocupações fundamentais de seus pais para com a criança, tornam-se para esta um enigma que ela carrega consigo ao longo de sua vida adulta. Esse enigma estará na origem de uma curiosidade (epistemofilia) jamais satisfeita, de um desejo de saber e de um desejo de compreender, periodicamente reativados pelas conjunturas materiais e morais cuja forma evoca as preocupações parentais (DEJOURS,1996).

Dejours (1996), observa também que o trabalho é a ocasião de transportar o cenário original do sofrimento para a realidade social. Os parceiros deste cenário não são mais os pais. São os trabalhadores, outros adultos. E o objetivo não é unicamente o prazer de um jogo, mas a ação no campo da produção, das relações sociais e do político. Decorre daí, na abordagem dejouriana, uma passagem do teatro psíquico ao teatro do trabalho que corresponde às mudanças de objeto e de fim (pulsões). Destinos pulsionais próprios à sublimação, cujas etapas de construção são retraçadas em termos ontogenéticos (histórico de desenvolvimento e aprendizagem). Essas transposições entre o teatro psíquico e o teatro do trabalho não são automáticas. Para que a última transposição seja possível, é preciso que exista entre o teatro do trabalho e o teatro psíquico herdado da infância, analogias de estrutura ou de forma. Entre o teatro da infância e o do trabalho interpõem-se diferenças ou desvios, que criam uma ambiguidade, um equívoco. $\mathrm{O}$ teatro do trabalho, para Dejours (2015), funciona como um relé, como uma ocasião de tornar a representar um cenário próximo do cenário inicial do sofrimento. Tentando entender a relação entre organização do trabalho e suas implicações para os trabalhadores Dejours (2015) adverte que a organização científica do trabalho não se limita a uma desapropriação do saber. Ela amordaça a liberdade de organização, de reorganização ou de adaptação do trabalho. Dessa forma, a análise das organizações necessita desvendar o mundo do poder e as formas de controle que ele impetra para se sentir autorizada a compreender essas organizações e suas finalidades (FARIA, 2007). A escuta do sofrimento originado no trabalho possibilita o estudo dessas relações de poder neste ambiente, dentro das instituições, assim como das práticas institucionais, suas leis de funcionamento, cultura e campos de forças que se impõem aos indivíduos e que contribuem com o sofrimento no trabalho (GÓMEZ et al, 2016 e GÓMEZ, 2017). Em seus estudos Dejours (1996, 2004 e 2015) tem observado que diante do sofrimento relacionado com a organização do trabalho, a maioria dos trabalhadores não evoluíam para doenças mentais graves, permanecendo num estado de equilíbrio, numa normalidade.

É essa relação e suas implicações que Dejours (2015) observa que a organização do trabalho opera, realçando como esta se apresenta perante a liberdade de organização, de reorganização ou de adaptação do sujeito no trabalho. Encontramos aqui o que Facas (2007) adverte que 
a PdT deve explorar ao analisar as organizações, o desvendamento do mundo do poder e de suas formas de controle que o sujeito internaliza para se sentir autorizado a compreender essas organizações e suas finalidades. Escutar o sofrimento internalizado pelos sujeitos é o caminho teórico adotado pela PdT. É através da escuta que, conforme Gómez (2016 e 2017), é possível o estudo das relações de poder, entendo com este se expressa mediante o funcionamento de suas práticas e de sua cultura nas organizações, resultando no sofrimento, ou no prazer, vivido no trabalho.

Em Alves (2014), o sentido do trabalho constitui-se elemento estruturante da subjetividade, e, por conseguinte, da própria saúde psíquica. Essa estruturação tem operado uma forma de precarização dos modos de produção centrados em elevada competitividade, que caracteriza o tipo de ética nas relações profissionais e os estilos de gestão contemporâneo.

Ainda conforme Dejours (2011a), esse equilíbrio ou normalidade é a capacidade que o sujeito possui de transformar seu sofrimento no trabalho em prazer e está relacionado com a mobilização subjetiva. Esta, por sua vez, se caracteriza pela forma com que o sujeito se engaja, ou se implica, na construção e evolução da organização do trabalho em termos de esforços de inteligência e de construção de discursos que descrevem a melhor maneira de superar as contradições e as dificuldades.

Na tentativa de ajuste dessas dificuldades vividas pelos trabalhadores, os estudos indicam que o sujeito adiciona, ao trabalho prescrito, inúmeras formas para superar os problemas que afetam a execução das tarefas (Facas, 2009; Santos Junior, 2009; Alves, 2014). Anjos (2013) observa que a organização do trabalho inscreve elementos que expressam as representações sobre a divisão do trabalho, as normas, o tempo e o controle exigidos para o correto desempenho da tarefa. Ainda conforme o autor, a prescrição nem sempre corresponde ao trabalho real. O trabalho real é, portanto, um trabalho invisível, ou mesmo transgressor da prescrição e, constitui-se, uma face da relação que o sujeito estabelece com a organização do trabalho. A discrepância entre o trabalho prescrito e o trabalho real favorece o sofrimento do sujeito (Anjos, 2013; Facas, 2009; Dejours, 2011b; Ferreira e Mendes, 2001; Alves, 2014).

Há um consenso estabelecido na comunidade de pesquisadores da PdT que adverte que o conceito de mobilização subjetiva não deve ser confundido com o conceito de estratégias defensivas. Enquanto a mobilização subjetiva tem como objeto de estudo o engajamento, as estratégias de defesa focam a forma com que opera a mediação, negação e enfrentamento do sofrimento (Dejours, Abdoucheli e Jayet, 1994). Dejours (2007) postula que há uma dupla face nas defesas e que elas podem fazer aceitável para o sujeito o que não deveria sê-lo. Funcionaria como armadilha que dessensibilizaria perante a fonte do sofrimento. Sobre isso Mendes (2007) alerta que as defesas podem perder seus efeitos e se transformarem em patologias sociais, como sobrecarga, servidão voluntaria e violência. Portanto, é possível vivenciar prazer 
Revista de Gestão Pública

quando se enfrenta uma pandemia reconhecidamente letal, quer seja como definidor de estrutura, divisor de atividades, ou legitimador social?

Estudos sobre mobilização subjetiva são escassos (Facas, 2017) e dentre os poucos trabalhos publicados destacam-se os estudos Mendes e Duarte (2013); Giongo et al (2015); Ferreira e Mendes (2001); e Eberle e Bruning (2013). A maioria dos autores abordam o reconhecimento, a inteligência prática, o espaço coletivo de discussão, a cooperação e a ressonância simbólica como elementos desenvolvidos pelos trabalhadores na tentativa de transformar e adequar a organização do trabalho às suas particularidades. Assim, optamos por seguir o direcionamento do estudo de Borowski et al (2017) em relação as dimensões da mobilização subjetiva utilizadas nesse trabalho. São elas: i) enfrentamento; ii) inteligência prática; iii) cooperação; iv) reconhecimento; e, v) espaços de discussão.

Tabela 1 - Categoria da Mobilização Subjetiva

\begin{tabular}{|c|c|}
\hline Enfrentamento & $\begin{array}{l}\text { O enfrentamento pode ser entendido como algo que procura modificar o que gera o sofrimento. É quando o } \\
\text { trabalhador consegue reconhecer aquilo que gera o sofrimento e age para alterar a origem do problema (Ramos } \\
\text { e Mendes, 2013). E diferente de estratégia de defesa. O enfrentamento é um tipo de mobilização subjetiva. O seu } \\
\text { conceito está dentro da Mobilização Subjetiva, o contrário não. Atitudes que fomentem um pensamento crítico } \\
\text { diante do prescrito de trabalho representam uma forma de enfrentamento importante para a saúde mental de } \\
\text { trabalhadores. Este potencial é a forma mais eficaz de lidar com o sofrimento ou canalizar a energia para manter } \\
\text { a saúde mental e pode ser praticado de diversos modos (Vieira, 2014). }\end{array}$ \\
\hline $\begin{array}{c}\text { Inteligência } \\
\text { prática }\end{array}$ & $\begin{array}{l}\text { A inteligência prática, compreendida pela capacidade do trabalhador em imprimir sua marca na obra } \\
\text { desenvolvida, está relacionada à audácia do trabalhador em transformar o prescrito no real, utilizando sua } \\
\text { reflexão e pensamento para elaborar, engendrar aquilo (Vieira, 2014; Duarte e Mendes, 2015). Esse processo } \\
\text { pode ocorrer devido à realidade de trabalho que propicia espaços de inteligência prática. }\end{array}$ \\
\hline Cooperação & $\begin{array}{l}\text { Para Dejours (2004), a cooperação se dá a partir do desejo das pessoas em estarem juntas, trabalhando e } \\
\text { superando as contradições presentes no contexto laboral. A vontade coletiva é um fator que não pode ser } \\
\text { prescrito e depende da liberdade conquistada no contexto laboral. Para esta relação de cooperação, é preciso que } \\
\text { a confiança faça sentido, através de acordos e normas que favoreçam este reconhecimento (Duarte e Mendes, } \\
\text { 2015). A colaboração ocorre no grupo como um todo, propiciando um espaço coletivo de trabalho, instigando } \\
\text { o desenvolvimento conjunto. Para Mendes (2007), o coletivo de trabalho pressupõe a equidade, a confiança e a } \\
\text { solidariedade, bem como a valorização do esforço conjunto na realização da tarefa. }\end{array}$ \\
\hline Reconhecimento & $\begin{array}{l}\text { O reconhecimento pressupõe uma valorização das atitudes e práticas laborais, por parte da gestão e/ou colegas } \\
\text { de trabalho. Envolve o julgamento dos colegas (julgamento da beleza) e/ou a percepção de utilidade dentro do } \\
\text { trabalho desenvolvido (julgamento da utilidade). Para Mendes (2007, p.45), o reconhecimento "é um dos modos } \\
\text { de fortalecimento da estrutura psíquica e da saúde", mas também complementa que por outro lado, ele "pode } \\
\text { ser um modo de captura dos trabalhadores nas armadilhas da dominação" (Idem). }\end{array}$ \\
\hline
\end{tabular}


FONTE: adaptado de Borowski et al (2017)

\section{O PRAZER NO tRABALHO}

Analisar os depoimentos, dos sujeitos deste estudo, sobre as situações de trabalho e influência em suas qualidades de vida, se reveste de significativa importância atual, especialmente por estes atuarem na linha de frente ao combate da Covid-19 na Itália, um país desenvolvido e um dos mais afetados. Estes profissionais, enquanto indivíduos plenos, trabalham para realizar suas necessidades sociais e psíquicas, sejam elas de sobrevivência, realização, sublimação ou outras. No entanto, para realizar seu trabalho, um indivíduo estabelece vínculos, o que é um componente das relações sociais e afetivas e refere-se diretamente à subjetividade humana (FARIA e SCHMITT, 2007). Estes indivíduos se vinculam à organização para satisfazer o que está na base de sua constituição: suas pulsões.

Para satisfazerem as pulsões e minimizarem o estado de tensão que elas causam, eles se dirigem a um objeto, através do qual poderão satisfazê-las. Nesse sentido, a organização, bem como os elementos que proporcionam, são vistas como objetos que podem satisfazer as pulsões individuais (FARIA e SCHMITT, 2007). A angústia provocada pela onipresença dos controles, pelo caráter ilimitado e inatingível das exigências, é compensada, conforme preconizado por Pagès et al (1987), pelos múltiplos prazeres que a organização oferece, especialmente os prazeres do tipo agressivo, o prazer de conquistar, de dominar os medos, os colegas, os demais membros da comunidade, de se superar e de se autodominar.

Uma das dimensões do trabalho é o prazer. Esse prazer emerge quando o trabalho cria identidade. Surge também quando possibilita aprender sobre um fazer específico, criar, inovar e desenvolver novas formas para execução da tarefa, bem como são oferecidas condições de interagir com os outros, de socialização e transformação do trabalho (MENDES, 2007). O sofrimento no trabalho começa quando, apesar de seu zelo, o trabalhador não consegue dar conta da tarefa. $O$ prazer, ao contrário, começa quando, graças a seu zelo, o trabalhador consegue inventar soluções convenientes (DEJOURS, 2012).

Vivenciar o prazer no trabalho não depende do querer, depende das condições nas quais o trabalho é realizado, da natureza da tarefa e do tipo de exigências que envolvem livre e igualmente as capacidades do indivíduo, não sendo praze- 
rosa uma atividade restringida por forças externas e que exija um gasto de energia maior do que o indivíduo seja capaz de criar (MENDES, 2007). A estrutura inconsciente de seus impulsos e de seus sistemas de defesa é ao mesmo tempo modelada pela organização e se insere nela, de tal forma que o indivíduo reproduz a organização, não apenas por motivos racionais, mas por razões mais profundas, que escapam a sua consciência. A organização tende a se tornar fonte de sua angústia e de seu prazer (DEJOURS, 2015; PAGÈS et al, 1987). Assim, a PdT, ao tentar entender a ação do sujeito em um contexto determinado de trabalho, sabe que todo comportamento é motivado e tem um sentido. Se uma certa conduta é insólita, isso se deve ao sofrimento subjetivo e às estratégias defensivas contra esse sofrimento. A inteligibilidade desse ato do sujeito vem não da conduta que ele expressa, mas do sofrimento que o motiva (LANCMAN e UCHIDA, 2003).

\section{CORPUS DA PESQUISA}

O corpus da investigação foi constituído por relatos de enfermeiros intensivistas italianos, com diferentes formas de sofrimento diante da organização do trabalho, evidenciando suas frustrações, decepções, gozos e prazeres. Estes relatos estão registrados em reportagem postada em 26/05/2020 pela BBC Brasil'. Há seis depoimentos presentes na reportagem, um não tem contribuição direta com o objetivo aqui trabalhado. $\mathrm{O}$ material selecionado traz cinco relatos de enfermeiros intensivistas italianos, atuantes durante o auge da Covid-19 naquele país, que compõe o corpus empírico da pesquisa. Estes depoimentos nos permitiram visualizar como a mobilização subjetiva operou diante da organização do trabalho, e como os recursos emocionais foram recrutados enquanto estratégia defensiva de cada um. Mas não permite fazer generalizações das conclusões aqui tiradas.

A metodologia utilizada foi modelada de forma que a unidade do discurso selecionado nos depoimentos, fosse uma unidade intencional do tema. Essa intenção se referiu a interação do deslocamento (originário da abordagem freudiana), com a proposta dejouriana de organização do trabalho (trabalho prescrito e trabalho real) e tendo como parâmetro as categorias de mobilização subjetiva apresentadas na tabela 1. Esses fenômenos se operam através do deslocamento que consistiu na identificação, nos discursos dos enfermeiros, da transferência de energia de uma representação para outra. As representações aqui tratadas são registros psíquicos decorrentes de objetos, situações, sensações, relações etc. Os elementos da mobilização subjetiva foram observados nas interseções com os deslocamentos.

A partir de Bioni (2019) optou-se por anonimizar os sujeitos, mesmos que seus relatos sejam públicos, preservando, assim, suas éticas e subjetividades. O fato de se aproveitar os depoimentos destes sujeitos, de livre acesso ao público, já evidencia uma não invasão de suas pri-

7 https://www.bbc.com/portuguese/internacional-52809097, acesso em 20/06/2020. 
vacidades. Ao mesmo tempo em que prescinde de prévia autorização de comissão de ética face a natureza pública dos dados e do anonimato dos sujeitos. Ainda na linha de anonimização das identidades, neste trabalho, estes sujeitos serão tratados com a letra D para se referir a depoente. Após a letra $\mathrm{D}$ será acrescido um número. O objetivo deste número é diferenciar um depoente de outro. Por mais que se possa sofisticar as análises desses relatos, essa sempre será incompleta. A natureza do dado secundário não permite fazer aprofundamentos e checagens para entender com clareza quais as cadeias de significações das representações operam os deslocamentos nas narrativas. A visualização dos conteúdos que vem do inconsciente fica, parcialmente, prejudicada. Mas não impediu que fosse identificada uma trilha teórica consistente que permitiu reflexões importantes.

\section{DO HERÓI AO ESQUECIDO}

"Estou mais irritado... Fico com raiva mais facilmente e começo brigas. Embora a emergência esteja diminuindo, nos sentimos cercados pela escuridão", relata D1. D2 declara que: "As coisas estão muito mais difíceis agora do que durante a crise. Tínhamos um inimigo para lutar. Agora que tenho tempo para refletir, me sinto tão perdida, sem rumo". O que estamos vendo aqui? Como essas emoções ganharam esse espaço? Há linhas de raciocínio que nos indicariam estarmos diante de Transtorno do Estresse Pós Traumático (TEPT), decorrente da exposição dos indivíduos a um evento estressante intenso. O enfrentamento da Covid-19 preenche bem este requisito de TEPT. Mas não é a TEPT que chama atenção aqui. Nestes dois depoimentos iniciais o que vemos são indícios de que recursos emocionais já se encontravam antes do evento traumático. As expressões estou mais e mais facilmente no depoimento de D1 e a expressão estão muito mais no depoimento de D2, denunciam que já havia um quadro psíquico com potencial para o desequilíbrio emocional. A Covid-19, ao que tudo indica, intensificou tal estado. Em D1 o termo mais intensificou o adjetivo irritado. $\mathrm{O}$ outro termo mais, no mesmo relato, intensificou o sentido do adverbio facilmente. Em D2 o termo muito adiciona mais energia ao adjetivo difícil, que já recebia a intensificação produzida pelo termo mais que lhe antecedia. Estas constatações nos dão segurança para adentrarmos na interpretação de eventos anteriores à TEPT. O que as evidências então nos mostram? Parecem indicar que estamos diante de fenômeno relacionado à organização do trabalho e as formas de mobilização subjetivas empreendidas pelos trabalhadores. As cargas emocionais, representadas pelos adjetivos e as energias que se acoplam à estas cargas, representadas pelos advérbios de intensidade, nos deixam pistas que a organização do trabalho e os recursos emocionais mobilizados, requerem uma interpretação à luz da PdT. Iniciemos pelos advérbios de intensidade. A presença deles implica considerar que o fluxo de energia já circulava antes do evento Covid-19. O evento Covid-19 apenas ajudou 
a ampliar tal circulação. $\mathrm{O}$ conceito de energia aqui empregado vem da psicanálise freudiana, para a qual se refere o fluxo da libido, que procura de forma catártica, irromper as barreiras dos mecanismos de defesa inconscientes para aflorar no Ego, parte racional da consciência.

Vejamos alguns exemplos que corroboram isso. "Quando eles estavam com medo de morrer, de repente todos nós nos tornamos heróis, mas eles já nos esqueceram". Neste relato, D2 se refere aos pacientes e as pessoas que aplaudiam, todas as tardes, o esforço que faziam. D1 faz colocação semelhante: "não sou herói, mas isso me fez sentir importante". Em outro relato temos: “Todo o estresse acumulado nas últimas semanas está se revelando agora. Eu tenho insônia e pesadelos. Acordo 10 vezes por noite com o coração disparado e sem fôlego", desabafa D2. D3 assim se expressa: "não tenho mais certeza de que quero ser enfermeira. Vi mais pessoas morrerem nos últimos dois meses do que em seis anos inteiros". D4 desabafa: "em março éramos heróis. Agora já fomos esquecidos". Este sentimento é compartilhado por D5 que afirma: "sinto-me carregada de raiva. Quero ir até eles e gritar na cara deles, dizer que estão colocando todos em perigo. É tão desrespeitoso comigo e todos os meus colegas". Este desabafo é direcionado às pessoas que não usam máscaras e não respeitam o distanciamento social e que se aglomeram em bares por toda Itália.

Em algum grau os depoimentos acima reivindicam respostas a situações vivenciadas por estes enfermeiros. O herói esquecido, os aplausos encerrados, a insônia, o pesadelo, a incerteza da profissão e a raiva, apontam, a partir da psicanálise freudiana, para o mesmo ponto: o objeto a qual a libido estava investida, não é mais percebido retornando a cumplicidade dos amantes, dito de outra forma, a relação incestuosa, edipiana, dos filhos com seus pais. Dejours (1996) propõe para situações semelhantes a essas, a convocação de uma compreensão, tal qual empreendida pela criança quando se percebe em terra incógnita, da experiência dolorosa da angústia, da solidão e do abandono - da rejeição de seus pais. $\mathrm{O}$ descompasso entre objeto e sujeito, que norteiam os investimentos libidinais, implicam que a energia pulsional não mais encontra ressonância na produção do trabalho de enfermagem, acarretando um acúmulo na organização psíquica destes trabalhadores. A consequência observada nos relatos é a construção de um discurso repleto de sentimentos de desprazer e dor que culminam em desilusões. São estas desilusões que aparecem como tensões incestuosas nesses relatos. Estes elementos se aproximam de Dejours et al (1994) ao evidenciarem que as capacidades de contenção, quando não conseguem reter estes conteúdos e estes são transbordados, implicam em uma liberação de energia que podem explicar as distintas sensações de dor e de angústia vivenciados pelos sujeitos. Tal liberação de energia encontrada nestes depoimentos, parecerem não apenas ecoar no esgotamento da inteligência prática destes profissionais, mas também parecem ressignificar a passagem do teatro psíquico ao teatro do trabalho. $\mathrm{O}$ destino das pulsões fica evidenciado que também é dirigido a pessoas que se 
quer são pacientes destes enfermeiros, mas possuem o potencial de o serem. Neste sentido vê-se aqui outra face da que foi apresentada por Pagès et al (1987), trata-se de uma agressividade vinda da sociedade para o interior das relações de trabalho, e não apenas o seu contrário.

Por mais que consigam evitar a antecipação de um futuro incerto (a transformação destas pessoas em pacientes) e de evitar transformar trabalho real em prescrito e trabalho prescrito em real, operando uma dupla hermenêutica, como uma parte desse real se origina do lado de fora do ambiente de trabalho, este aspecto tem potencial de drenar mais energia que a capacidade de reposição destes trabalhadores. Esta condição amplia o entendimento de Mendes (2007) para além do reconhecimento dos pares e da hierarquia. E amplia, também, o entendimento de Dejours (1994) ao adicionar que há um transportar do cenário original do sofrimento que decorre da realidade social e não apenas para esta realidade. A sensação de esgotamento e de desilusão, presentes nestes discursos, emergem com características que o diferenciam da abordagem tradicional da inteligência prática, qual seja, daquela em que a organização do trabalho se estrutura na divisão das tarefas e dos sujeitos no mundo do trabalho. Como parte dessa inteligência prática, que implica a audácia na transformação do trabalho prescrito em real, decorre dessa desilusão com essas pessoas (potenciais pacientes), temos aqui uma situação que vai além da divisão de tarefas e dos trabalhadores. Essa situação implica a requisição de habilidades e expertise funcional que extrapolam muito os pré-requisitos da prescrição, pois implicam o recrutamento de elementos que drenam os recursos emocionais que se presume aderente a inteligência prática. $O$ desejo de saber e o desejo de compreensão, que perpassam a inteligência prática, não se limitam ao interior da organização hospitalar em que atuam. A drenagem de recursos emocionais que os potenciais pacientes são capazes de operar sobre os enfermeiros, estão para além das fronteiras organizacionais. Não foi encontrado na literatura especializada algo correlato que possa melhor explicar o que aqui foi achado, este para além das fronteiras organizacionais.

Em outro discurso temos D2: "Voltaremos a ser vistos como pessoas que limpam bundas, preguiçosas e inúteis". A presença do verbo voltar convoca ao mesmo tempo a noção de deslocamento e de diacronia dos registros. Em algum momento de sua história singular D2 se via exatamente desse jeito. Se colocar na linha de frente da Covid-19 lhe permitiu, temporariamente, reviver a experiência, no campo do registro imaginário (teatro psíquico), de uma utilidade, de um reconhecimento, de um esforço pessoal para dominar técnicas, agora no campo da enfermagem (teatro do trabalho), que sem estas, as pessoas, que D2 se projeta e se identifica (os outros adultos), não conseguiriam êxito em seus tratamentos. $\mathrm{O}$ adjetivo inútil reforça o registro da realidade operando a confrontação com a fantasia (registro imaginário). A visível mensagem de desesperança em D2 é consistente com a categoria reconhecimento presente no trabalho de Borowski et al (2017). Para estes 
autores o reconhecimento pressupõe uma valorização das atitudes e práticas laborais, por parte da gestão e/ou colegas de trabalho. Cabe ressaltar aqui que esse reconhecimento está atrelado, em grande medida, ao contexto decorrente da pandemia. Ele equivale a um valor atribuído além do que há no contexto normal, contemplando as "pessoas que aplaudiam" e que estão para além das fronteiras organizacionais. Envolve, ainda, o julgamento dos colegas (julgamento da beleza) e/ou a percepção de utilidade dentro do trabalho desenvolvido (julgamento da utilidade). O plural do verbo voltar em D2 alude ao julgamento de beleza que ela se coloca junto com seus colegas. Os adjetivos que qualificam este voltar aludem ao julgamento de utilidade que D2 não aceita.

Na linha dos julgamentos temos também o depoimento de D5: "sinto-me carregada de raiva. Quero ir até eles e gritar na cara deles, dizer que estão colocando todos em perigo. É tão desrespeitoso comigo e todos os meus colegas". O esforço de mobilização subjetiva no depoimento de D5 é convergente com a categoria enfrentamento, uma vez que há uma tentativa, latente, através da utilização do verbo ir que almeja modificar o fato gerador de sofrimento, aqui representada pela expressão quero que é a inflexão do verbo querer em sua primeira pessoa. Mas aqui também se observa, nessa categoria, o mesmo já registrado na categoria inteligência prática, ou seja, não há registros teóricos que possam explicar esta parte da organização do trabalho que extrapola as divisões de tarefas e dos trabalhadores, uma vez que o verbo ir utilizado por D5 faz alusão a um espaço fora dos limites institucionais do hospital. E neste espaço exterior há elementos decorrentes de investimentos da libido que não ecoam, no espaço interior do hospital, gratificação e prazer. Semelhante ao discurso de D2 a presença dos verbos ir e querer convocam ao mesmo tempo a existência de um deslocamento e de uma diacronia dos registros imaginários operando em D5. D5 não estaria, apenas, querendo ir ao encontro destas pessoas, o deslocamento aqui identificado é o sentido do investimento da libido.

Os objetos (pessoas) que antes aplaudiam, agora se aglomeram. O que antes era percebido como um retorno do investimento libidinal, agora é percebido como um investimento sem retorno esperado. Isso é potencialmente frustrante. De acordo com os preceitos freudianos não há perda da energia libidinosa, esta retorna ao sujeito desejante sob forma de raiva e de agressividade (inscrita nos registros imaginários com a convocação feita, porém não verbalizada, da palavra vontade), "quero ir lá e gritar na cara deles". A expressão quero ir lá, oculta a convocação da vontade, enquanto ação pretendida e fantasiada, para lidar com a frustração e agressividade vivida como realidade psíquica por D5. A presença do verbo gritar e seu alvo, a cara deles, são indícios dessa agressividade retornando ao sujeito que fizera, anteriormente, uma projeção de que aqueles objetos (pessoas que denegam o desejo) que se aglomeram representam os mesmos objetos (pessoas que reinvestem o desejo) que aplaudiam.

Importa reforçar aqui que ambos os julgamentos, em ambos 
os depoimentos de D2 (implícito) e de D5 (explícito), e no conjunto de sensações de esgotamento e de desilusões relatados, extrapolam o ambiente institucional da organização do trabalho. No trabalho de Gómez (2017) os clientes e acontecimentos inesperados são pontuados nas situações de trabalho, mas não tensionam os limites institucionais da organização do trabalho. Nos relatos dos enfermeiros intensivistas, fica claro haver um para além das fronteiras organizacionais na delimitação da organização do trabalho, assim como há uma fronteira específica e inédita que dilata a discrepância (ANJOS, 2013; FACAS, 2013; DEJOURS, 2011b; FERREIRA e MENDES, 2001) entre trabalho prescrito e trabalho real na estruturação do sofrimento dos sujeitos. São os pacientes e pessoas nos bares, sujeitos não vinculados a esta organização do trabalho, logo, sujeitos que ainda não estão contemplados por essa fronteira, mas que conseguem interferir no processo de reconhecimento que irá fazer parte da modelagem da prescrição do trabalho e do trabalho real destes trabalhadores.

Os elementos da mobilização subjetiva que foram encontrados, nos depoimentos aqui analisados, são: enfrentamento, inteligência prática e reconhecimento. Os outros dois elementos não foram identificados. Os elementos da mobilização subjetiva identificados estão na intersecção com o deslocamento, e, são frutos dos investimentos reinvestidos e denegados. Há algo neste para além desta fronteira organizacional e desta lógica de divisões que interfere, de forma transversal a prescrição e ao real do trabalho, que de alguma forma integram o recrutamento dos recursos emocionais dos enfermeiros para o enfrentamento da Covid-19. Implica admitir que inerente a estes elementos, o conceito de trabalho prescrito e trabalho real não se mostraram restritos a lógica das divisões de tarefas e dos trabalhadores, primordiais, na edificação da categoria organização do trabalho, preconizada por Dejours. Este aspecto, aqui chamado de para além, doravante chamaremos de transversalidade, não é previsto em Dejours e não foram identificados trabalhos que o aborde.

Há uma significativa quantidade de energia importada de elementos que não compõem a organização do trabalho tradicional. Estas importações variam de reinvestimentos da libido até a denegação desse investimento. Isso difere de aspectos relativos e que são inerentes à profissão de enfermeiro, circunscritos aos domínios organizacionais. Nestes domínios os enfermeiros estão expostos a críticas, elogios e assemelhados vindos de médicos, da gestão, de pacientes, dos familiares e amigos dos pacientes que estão internados. Mas não é apenas isso que observamos aqui. Trata-se de uma troca de energia emocional até com potenciais pacientes (que podem, inclusive, não se transformarem em pacientes destes enfermeiros), exteriores aos domínios organizacionais, aqueles que se aglomeram nos bares, que aplaudiam e que não usavam máscaras. Importa frisar que as evidências apontam para imagos (imagem inconsciente de objeto, idealizada em estádios infantis e que fica investida pulsionalmente) decorrentes de internalizações 
dos enfermeiros, de conteúdos introjetados, e não para sujeitos reais (potenciais pacientes). Os elementos da prescrição e até do real do trabalho, que estão circunscritos na categoria organização do trabalho, tradicionalmente usada na PdT, são aqui questionados se são os únicos a instituírem as divisões das tarefas e dos trabalhadores, no interior do ambiente de trabalho.

A organização do trabalho, tal qual definida por Dejours, é inerente ao alcance institucional do trabalho prescrito, não lhe ultrapassando. Admitir a transversalidade, é admitir uma face específica do real do trabalho que ultrapassa as fronteiras institucionais. A transversalidade é assim um aspecto particular da organização real do trabalho que aqui é observado. Ela está, conforme as evidências observadas, ao mesmo tempo dentro e fora dos limites institucionais. Ela não modela o exterior da instituição. Mas seu interior, há uma dimensão ou faceta do trabalho prescrito e do real que dela decorre e que é modelado pelo exterior, que é a própria sociedade e as imagos que os sujeitos constroem e introjetam. Ela aqui se evidencia com potencial de antecipar estados emocionais futuros e que levam os enfermeiros ao esgotamento de si mesmos na presente situação da pandemia. Estes trabalhadores podem estar antecipando estes estados emocionais em decorrência de que precisam continuar trabalhando, rotineiramente, no mesmo lugar em que já sofreram, ou se desgastaram emocionalmente, pois este é seu emprego, seu trabalho, seu sustento. Esta necessidade de continuar no mesmo lugar que sofrem, ocorre ao mesmo tempo em que os indivíduos, que são percebidos desrespeitando as recomendações das autoridades sanitárias, têm a probabilidade de se transformarem em seus pacientes, carregando consigo impressões prévias, por parte dos enfermeiros, de indivíduos que desrespeitaram seus esforços e privações emocionais. Processos projetivos e introjetivos reivindicando, nos registros imaginários, o retorno do investimento da libido e a recusa por sua denegação, parecem fazer parte desta transversalidade do real trabalho no contexto da pandemia.

O fenômeno da mobilização subjetiva, aqui estudado, importa considerar que os sujeitos investem sua libido através de projeções não apenas nos objetos (pessoas que reinvestem o desejo) presentes nos limites institucionais do trabalho. Há investimentos feitos em objetos (pessoas que denegam o desejo) que estão para além das fronteiras institucionais. Logo a mobilização subjetiva está, simultaneamente, dentro e fora dos limites institucionais e acompanha os deslocamentos, via diacronia dos registros imaginários (fantasias e imagos) confrontados com os registros da realidade.

\section{CONSIDERAÇÕES FINAIS}

A transversalidade, aqui identificada como uma característica presente nos relatos dos enfermeiros, se refere a forma como os elementos da mobilização subjetiva enfrentamento, inteligência prática 
e reconhecimento se articularam, a partir dos deslocamentos, com a organização do trabalho. O conceito de mobilização subjetiva, tendo como pano de fundo uma pandemia planetária, permitiu visualizar possíveis ampliações teóricas sobre o conceito de real do trabalho que com ele se articula. Estudos que aprofundem a transversalidade devem ser realizados a fim de corroborar ou refutar sua relação com a lógica da organização do trabalho. O escopo metodológico empregado se mostrou válido ao mesmo tempo que evidenciou a importância dos deslocamentos e das pulsões, como categorias analíticas constitutivas da mobilização subjetiva. As oportunidades teóricas que se abrem aqui, implicam adentrar o terreno dos deslocamentos (diacronia dos registros imaginários) e das pulsões para teorizar a etiologia e nosografia do fenômeno sofrimento decorrente da mobilização subjetiva, ampliando, assim, seu escopo conceitual.

\section{REFERÊNCIAS}

ANJOS, F. B. dos. Organização do Trabalho. In: VIEIRA, F. de O. et al (Orgs.). Dicionário Crítico de Gestão e Psicodinâmica do Trabalho. Curitiba: Ed. Juruá, 2013. p.267-274.

ANTUNES, R.; PRAUN, L. A sociedade dos adoecimentos no trabalho. Revista Serviço Social $\mathcal{E}$ Sociedade, São Paulo, jul./set, n. 123, p. 407-427, 2015.

BAUMAN, Z. O Mal Estar da Pós Modernidade.

Rio de Janeiro: Editora Zahar, 1999. - Modernidade Líquida. Rio de Janeiro: Editora Zahar, 2001.

- Vida para Consumo - a transformação das pessoas em mercadoria. Rio de Janeiro: Editora Zahar, 2008.

BASTOS, A. V. B. et al. Significado do trabalho: um estudo entre trabalhadores inseridos em organizações formais. Revista de Administração de Empresas, São Paulo, v.35, n.6, p.20-29, 1995.

BIONI, B. R. Proteção de dados pessoais: a função e os limites do consentimento. Rio de Janeiro: Forense, 2019.

BOROWSKI, S. V. et al. Mobilização subjetiva e estratégias defensivas de trabalhadores metalúrgicos à luz da Psicodinâmica do Trabalho. Psicologia Argumento, Curitiba, v.35, n.88, p.1-15, 2017.

BOUYER, G. C. et al. Subjetivação e sofrimento no trabalho: o "si" que "se" produz na atividade. Revista Memorandum, Belo Horizonte, v.11, p.43-58, 2006

DEBORD, G. A Sociedade do Espetáculo. Rio de 
Janeiro: Contraponto Editora, 1997.

DEJOURS, C. A loucura do trabalho: estudo de psicopatologia do trabalho. São Paulo: Cortez, 2015.

Psicodinâmica do trabalho e teoria da sedução. Psicologia em Estudo, Maringá, v. 17, n. 3, p. 363-371, 2012.

Addendum: Da psicopatologia à psicodinâmica do trabalho. In: LANCMAN, S.; SZNELWAR, L. I. (Orgs.). Christophe Dejours: Da psicopatologia à psicodinâmica do trabalho. Rio de Janeiro: Editora Fiocruz, 2011a. p. 47-104.

. Ativismo profissional: Masoquismo, compulsividade ou alienação? In: LANCMAN, S.; SZNELWAR, L. I. (Orgs.). Christophe Dejours: Da psicopatologia à psicodinâmica do trabalho. Rio de Janeiro: editora Fiocruz, 2011b. p. 159-177.

. Psicodinâmica do trabalho na pós modernidade. In: MENDES, A. M. et al. (Org.). Diálogos em Psicodinâmica do Trabalho. Brasília: Pararelo 15, 2007. p. 13-26.

Subjetividade, trabalho e ação. Revista

Produção, São Paulo, v.14, n.3, p.27-34, 2004.

. Uma nova visão do sofrimento humano nas organizações. In: CHANLAT, J. F. O indivíduo na organização: dimensões esquecidas - v. 1. São Paulo: Atlas, 1996. p.150-173.

. et al. In: BETIOL, M. I. S. (coord.). Psicodinâmica do trabalho: contribuições da escola dejouriana à análise da relação prazer, sofrimento e trabalho. São Paulo: Atlas, 1994.

DUARTE, F. S.; MENDES, A. M. Da escravidão a servidão voluntaria: perspectivas para a clínica psicodinâmica do trabalho no Brasil. Farol: Revista de Estudos Organizacionais e Sociedade, Belo Horizonte, v. 2, n. 3, p. 68-128, 2015.

EBERLE, A. D.; BRUNING, C. Prazer e Sofrimento nas Organizações: um resumo introdutório à teoria psicodinâmica do trabalho. Revista Organização Sistêmica, Curitiba, v.4, n.2, 2013.

FACAS, E. P. et al. A Psicodinâmica do Trabalho na Região Centro-Oeste do Brasil. In: MONTEIRO, J. K. et al (Orgs). Psicodinâmica do Trabalho no Brasil: Práticas, Avanços e Desafios. Curitiba: Juruá, 2017. p.15-36. et al. Organização do trabalho e mediação do sofrimento de pilotos metroviários. Revista Laborativa, Botucatu, v. 2, n. 2, p.1-20, 2013.

FARIA, J. H. Os fundamentos da teoria crítica: uma 
introdução. In: FARIA, J. H. (Org.). Análise Crítica das Teorias e Práticas Organizacionais. São Paulo: Atlas, 2007. p.1-20.

FARIA, J. H.; SCHMITT, E. C. Indivíduo, Vínculo e Subjetividade. In: FARIA, J. H. (Org.). Análise Crítica das Teorias e Práticas Organizacionais. São Paulo: Atlas, 2007. p. 54-82.

FERREIRA, M. C.; MENDES, A. M. “Só de pensar em vir trabalhar, já fico de mau humor": atividade de atendimento ao público e prazer-sofrimento no trabalho. Estudo de Psicologia, Natal, v. 6, n. 1, p. 93-104, 2001.

GIONGO, C. R. et al. Psicodinâmica do trabalho no Brasil: revisão sistemática da literatura. Temas em Psicologia, Ribeirão Preto, v. 23, n. 4, p. 803-814, 2015.

GÓMEZ, V. A. et al. A palavra como laço social na clínica psicodinâmica do trabalho. Contextos Clínicos, São Leopoldo, v. 9, n. 2, p. 253-264, 2016.

Desamparo e sofrimento no trabalho bancário: um estudo de caso em clínica do trabalho. Dissertação (mestrado PSTO Mestrado em Psicologia Social, do Trabalho e das Organizações - PSTO (Dissertações) - Universidade de Brasília, Brasília. 2017.

GAULEJAC, V. de. Gestão como doença social: Ideologia, poder gerencialista e fragmentação social. São Paulo: Editora Ideias \& Letras, 2007.

LANCMAN, S.; UCHIDA, S. Trabalho e subjetividade: o olhar da psicodinâmica do trabalho. Cadernos de Psicologia Social do Trabalho, São Paulo, v. 6, dez, p. 79-90, 2003.

LIMA, M. E. A. Trabalho e Identidade: uma reflexão à luz do debate sobre a centralidade do trabalho na sociedade contemporânea. Educação E Tecnologia, Belo Horizonte, v. 12, n.3, p. 05-09, 2007.

MENDES, A. M. Psicodinâmica do Trabalho: Teoria, Método e Pesquisas. São Paulo: Casa do Psicólogo, 2007. ; DUARTE F. S. Mobilização Subjetiva. In: VIEIRA, F. de O. et al (Orgs.). Dicionário Crítico de Gestão e Psicodinâmica do Trabalho. Curitiba: Juruá, 2013. p.259-262.

MERLO, Á. R. C. Prefácio. In: MONTEIRO, J. K. et al (orgs.). Psicodinâmica do Trabalho no Brasil: Práticas, Avanços e Desafios. Curitiba: Juruá, 2017.

MONTEIRO, D. de A. O sujeito do consumo e os laços afetivos. Cogito, Salvador, v. 6, p. 61-65, 2004. 
PAGÈS, M. et al. O poder das organizações. São Paulo: Atlas, 1987.

RAMOS, L. V.; MENDES, A. M. A Dinâmica da Cooperação entre Gestores de uma Empresa Multinacional. Revista Gestão E Tecnologia, Pedro Leopoldo, v. 13, n. 3, p. 128-150, 2013.

SILVA, R. V. S. et al. A relação entre reconhecimento, trabalho e saúde sob o olhar da Psicodinâmica do Trabalho e da Clínica da Atividade: debates em psicologia do trabalho. Gerais: Revista Interinstitucional de Psicologia, Juiz de Fora, v. 8, n. 2, p. 415-427, 2015.

VIEIRA, F. de O. "Quem vê cara, não vê coração": aspectos discursivos e eufemísticos da sedução organizacional que disfarçam violência e sofrimento no trabalho. Revista Economia E Gestão, Belo Horizonte, v. 14 n. 36, p. 194-220, 2014. 